\title{
Common Fixed Points for Multivalued Mappings in Complex Valued Metric Spaces with Applications
}

\author{
Jamshaid Ahmad, ${ }^{1}$ Chakkrid Klin-Eam, ${ }^{2}$ and Akbar Azam ${ }^{1}$ \\ ${ }^{1}$ Department of Mathematics, COMSATS Institute of Information Technology, Chak Shahzad, Islamabad 44000, Pakistan \\ ${ }^{2}$ Department of Mathematics, Faculty of Science, Naresuan University, Phitsanulok 65000, Thailand
}

Correspondence should be addressed to Chakkrid Klin-Eam; chakkridk@nu.ac.th

Received 31 July 2013; Revised 21 November 2013; Accepted 24 November 2013

Academic Editor: Irena Rachůnková

Copyright (C) 2013 Jamshaid Ahmad et al. This is an open access article distributed under the Creative Commons Attribution License, which permits unrestricted use, distribution, and reproduction in any medium, provided the original work is properly cited.

In this paper, we introduce the notion of multivalued contractive mappings in complex valued metric space and prove common fixed point theorems for two multivalued contractive mappings in complex valued metric spaces without using the notion of continuity. Our results improve and extend the results of Azam et al. (2011).

\section{Introduction}

The Banach fixed point theorem was used to establish the existence of a unique solution for a nonlinear integral equation [1]. Moreover, this theorem plays an important role in several branches of mathematics. For instance, it has been used to show the existence of solutions of nonlinear Volterra integral equations and nonlinear integrodifferential equations in the Banach spaces and to show the convergence of algorithms in computational mathematics. Because of its importance and usefulness for mathematical theory, it has become a very popular tool of mathematical analysis in many directions. Nadler [2] introduced the concept of multivalued contraction mappings and obtained the fixed points results for multivalued mappings. Huang and Zhang [3] introduced the notion of cone metric space which is a generalization of metric spaces. They extended Banach contraction principle to cone metric spaces. Since then, Arshad et al. [4], Azam and Arshad [5], Latif and Shaddad [6], Karapınar [7], and many others obtained fixed point theorems in cone metric spaces (see [8]).

The fixed point results regarding rational contractive conditions cannot be extended in cone metric spaces. Azam et al. [9] introduced the concept of complex valued metric spaces and obtained sufficient conditions for the existence of common fixed points of a pair of mappings satisfying contractive type condition involving rational inequalities. In the same way, Rouzkard and Imdad [10] established some common fixed point theorems satisfying certain rational expressions in complex valued metric spaces which generalize, unify, and complement the results of Azam et al. [9]. Recently, Sintunavarat and Kumam [11] obtained common fixed point results by replacing constant of contractive condition with control functions. For more details in the subject, we refer to [12-19].

The aim of this paper is to extend the results of Azam et al. [9] to multivalued mappings in complex valued metric spaces.

\section{Preliminaries}

Let $\mathbb{C}$ be the set of complex numbers and $z_{1}, z_{2} \in \mathbb{C}$. Define a partial order $\lesssim$ on $\mathbb{C}$ as follows:

$$
\begin{gathered}
z_{1} \preccurlyeq z_{2} \quad \text { iff } \operatorname{Re}\left(z_{1}\right) \leqslant \operatorname{Re}\left(z_{2}\right), \\
\operatorname{Im}\left(z_{1}\right) \leqslant \operatorname{Im}\left(z_{2}\right) .
\end{gathered}
$$

It follows that

$$
z_{1} \preccurlyeq z_{2}
$$


if one of the following conditions is satisfied:

$$
\begin{array}{rll}
\text { (i) } & \operatorname{Re}\left(z_{1}\right)=\operatorname{Re}\left(z_{2}\right), & \operatorname{Im}\left(z_{1}\right)<\operatorname{Im}\left(z_{2}\right), \\
\text { (ii) } \operatorname{Re}\left(z_{1}\right)<\operatorname{Re}\left(z_{2}\right), & \operatorname{Im}\left(z_{1}\right)=\operatorname{Im}\left(z_{2}\right), \\
\text { (iii) } \operatorname{Re}\left(z_{1}\right)<\operatorname{Re}\left(z_{2}\right), & \operatorname{Im}\left(z_{1}\right)<\operatorname{Im}\left(z_{2}\right), \\
\text { (iv) } \operatorname{Re}\left(z_{1}\right)=\operatorname{Re}\left(z_{2}\right), & \operatorname{Im}\left(z_{1}\right)=\operatorname{Im}\left(z_{2}\right) .
\end{array}
$$

In particular, we will write $z_{1} \preccurlyeq z_{2}$ if $z_{1} \neq z_{2}$ and one of (i), (ii), and (iii) is satisfied and we will write $z_{1} \prec z_{2}$ if only (iii) is satisfied. Note that

$$
\begin{gathered}
0 \precsim z_{1} \preccurlyeq z_{2} \Longrightarrow\left|z_{1}\right|<\left|z_{2}\right|, \\
z_{1} \preceq z_{2}, z_{2} \prec z_{3} \Longrightarrow z_{1} \prec z_{3} .
\end{gathered}
$$

Definition 1. Let $X$ be a nonempty set. Suppose that a mapping $d: X \times X \rightarrow \mathbb{C}$ satisfies

(1) $0 \precsim d(x, y)$, for all $x, y \in X$ and $d(x, y)=0$ if and only if $x=y$;

(2) $d(x, y)=d(y, x)$ for all $x, y \in X$;

(3) $d(x, y) \precsim d(x, z)+d(z, y)$, for all $x, y, z \in X$.

Then $d$ is called a complex valued metric on $X$, and $(X, d)$ is called a complex valued metric space. A point $x \in X$ is called interior point of a set $A \subseteq X$ whenever there exists $0 \prec r \in \mathbb{C}$ such that

$$
B(x, r)=\{y \in X: d(x, y) \prec r\} \subseteq A .
$$

A point $x \in X$ is called a limit point of $A$ whenever for every $0 \prec r \in \mathbb{C}$,

$$
B(x, r) \bigcap(A \backslash\{x\}) \neq \phi .
$$

$A$ is called open whenever each element of $A$ is an interior point of $A$. Moreover, a subset $B \subseteq X$ is called closed whenever each limit point of $B$ belongs to $B$. The family

$$
F=\{B(x, r): x \in X, 0 \prec r\}
$$

is a subbasis for a Hausdorff topology $\tau$ on $X$.

Let $\left\{x_{n}\right\}$ be a sequence in $X$ and $x \in X$. If for every $c \in \mathbb{C}$ with $0 \prec c$ there is $n_{0} \in \mathbb{N}$ such that for all $n>n_{0}, d\left(x_{n}, x\right) \prec c$, then $\left\{x_{n}\right\}$ is said to be convergent, $\left\{x_{n}\right\}$ converges to $x$, and $x$ is the limit point of $\left\{x_{n}\right\}$. We denote this by $\lim _{n \rightarrow \infty} x_{n}=x$, or $x_{n} \rightarrow x$, as $n \rightarrow \infty$. If for every $c \in \mathbb{C}$ with $0 \prec c$ there is $n_{0} \in$ $\mathbb{N}$ such that for all $n>n_{0}, d\left(x_{n}, x_{n+m}\right) \prec c$, then $\left\{x_{n}\right\}$ is called a Cauchy sequence in $(X, d)$. If every Cauchy sequence is convergent in $(X, d)$, then $(X, d)$ is called a complete complex valued metric space. We require the following lemmas.

Lemma 2 (see [9]). Let $(X, d)$ be a complex valued metric space and let $\left\{x_{n}\right\}$ be a sequence in $X$. Then $\left\{x_{n}\right\}$ converges to $x$ if and only if $\left|d\left(x_{n}, x\right)\right| \rightarrow 0$ as $n \rightarrow \infty$.

Lemma 3 (see [9]). Let $(X, d)$ be a complex valued metric space and let $\left\{x_{n}\right\}$ be a sequence in $X$. Then $\left\{x_{n}\right\}$ is a Cauchy sequence if and only if $\left|d\left(x_{n}, x_{n+m}\right)\right| \rightarrow 0$ as $n \rightarrow \infty$.

\section{Main Results}

Let $(X, d)$ be a complex valued metric space.

We denote by $N(X)$ (resp., $C B(X)$ ) the set of nonempty (resp., closed and bounded) subsets of a complex valued metric space. Now, we denote $s\left(z_{1}\right)=\left\{z_{2} \in \mathbb{C}: z_{1} \preceq z_{2}\right\}$ for $z_{1} \in \mathbb{C}$, and $s(a, B)=\cup_{b \in B} s(d(a, b))=\cup_{b \in B}\{z \in \mathbb{C}$ : $d(a, b) \preceq z\}$ for $a \in X$ and $B \in C(X)$. For $A, B \in C(X)$, we denote

$$
s(A, B)=\left(\bigcap_{a \in A} s(a, B)\right) \bigcap\left(\bigcap_{b \in B} s(b, A)\right) .
$$

Remark 4. Let $(X, d)$ be a complex valued metric space. If $\mathbb{C}=$ $R$, then $(X, d)$ is a metric space. Moreover, for $A, B \in C B(X)$, $H(A, B)=\inf s(A, B)$ is the Hausdorff distance induced by $d$.

Let $(X, d)$ be a complex valued metric space and let $C B(X)$ be a collection of nonempty closed subsets of $X$. Let $T: X \rightarrow$ $C B(X)$ be a multivalued map. For $x \in X$ and $A \in C B(X)$, define

$$
W_{x}(A)=\{d(x, a): a \in A\}
$$

Thus, for $x, y \in X$

$$
W_{x}(T y)=\{d(x, u): u \in T y\} .
$$

Definition 5. Let $(X, d)$ be a complex valued metric space. A nonempty subset $A$ of $X$ is called bounded from below if there exists some $z \in \mathbb{C}$, such that $z \preceq a$ for all $a \in A$.

Definition 6. Let $(X, d)$ be a complex valued metric space. A multivalued mapping $F: X \rightarrow 2^{\mathbb{C}}$ is called bounded from below if for $x \in X$ there exists $z_{x} \in \mathbb{C}$ such that

$$
z_{x} \preceq u, \quad \forall u \in F x
$$

Definition 7. Let $(X, d)$ be a complex valued metric space. The multivalued mapping $T: X \rightarrow C B(X)$ is said to have lower bound property (l.b. property) on $(X, d)$ if for any $x \in X$, the multivalued mapping $F_{x}: X \rightarrow 2^{\mathbb{C}}$ defined by

$$
F_{x}(T y)=W_{x}(T y)
$$

is bounded from below. That is, for $x, y \in X$ there exists an element $l_{x}(T y) \in \mathbb{C}$ such that

$$
l_{x}(T y) \preceq u
$$

for all $u \in W_{x}(T y)$, where $l_{x}(T y)$ is called lower bound of $T$ associated with $(x, y)$.

Definition 8 . Let $(X, d)$ be a complex valued metric space. The multivalued mapping $T: X \rightarrow C B(X)$ is said to have the greatest lower bound property (g.l.b. property) on $(X, d)$ if the greatest lower bound of $W_{x}(T y)$ exists in $\mathbb{C}$ for all $x, y \in X$. We denote $d(x, T y)$ by the g.l.b of $W_{x}(T y)$. That is,

$$
d(x, T y)=\inf \{d(x, u): u \in T y\}
$$


Theorem 9. Let $(X, d)$ be a complete complex valued metric space and let $S, T: X \rightarrow C B(X)$ be multivalued mappings with g.l.b. property such that

$$
\begin{aligned}
& \lambda d(x, y)+\frac{\mu d(x, S x) d(y, T y)+\gamma d(y, S x) d(x, T y)}{1+d(x, y)} \\
& \quad \in s(S x, T y)
\end{aligned}
$$

for all $x, y \in X$ and $\lambda, \mu$, and $\gamma$ are nonnegative real numbers with $\lambda+\mu+\gamma<1$. Then $S, T$ have a common fixed point.

Proof. Let $x_{0}$ be an arbitrary point in $X$ and $x_{1} \in S x_{0}$. From (15), we have

$$
\begin{aligned}
& \lambda d\left(x_{0}, x_{1}\right) \\
& \quad+\frac{\mu d\left(x_{0}, S x_{0}\right) d\left(x_{1}, T x_{1}\right)+\gamma d\left(x_{1}, S x_{0}\right) d\left(x_{0}, T x_{1}\right)}{1+d\left(x_{0}, x_{1}\right)} \\
& \quad \in s\left(S x_{0}, T x_{1}\right) .
\end{aligned}
$$

This implies that

$$
\begin{aligned}
& \lambda d\left(x_{0}, x_{1}\right) \\
& \quad+\frac{\mu d\left(x_{0}, S x_{0}\right) d\left(x_{1}, T x_{1}\right)+\gamma d\left(x_{1}, S x_{0}\right) d\left(x_{0}, T x_{1}\right)}{1+d\left(x_{0}, x_{1}\right)} \\
& \quad \in\left(\bigcap_{x \in S x_{0}} s\left(x, T x_{1}\right)\right), \\
& \lambda d\left(x_{0}, x_{1}\right) \\
& \quad+\frac{\mu d\left(x_{0}, S x_{0}\right) d\left(x_{1}, T x_{1}\right)+\gamma d\left(x_{1}, S x_{0}\right) d\left(x_{0}, T x_{1}\right)}{1+d\left(x_{0}, x_{1}\right)} \\
& \in s\left(x, T x_{1}\right) \quad \forall x \in S x_{0} .
\end{aligned}
$$

Since $x_{1} \in S x_{0}$, we have

$$
\begin{aligned}
& \lambda d\left(x_{0}, x_{1}\right) \\
& \quad+\frac{\mu d\left(x_{0}, S x_{0}\right) d\left(x_{1}, T x_{1}\right)+\gamma d\left(x_{1}, S x_{0}\right) d\left(x_{0}, T x_{1}\right)}{1+d\left(x_{0}, x_{1}\right)} \\
& \quad \in s\left(x_{1}, T x_{1}\right), \\
& \lambda d\left(x_{0}, x_{1}\right) \\
& \quad+\frac{\mu d\left(x_{0}, S x_{0}\right) d\left(x_{1}, T x_{1}\right)+\gamma d\left(x_{1}, S x_{0}\right) d\left(x_{0}, T x_{1}\right)}{1+d\left(x_{0}, x_{1}\right)} \\
& \quad s\left(x_{1}, T x_{1}\right)=\bigcup_{x \in T x_{1}} s\left(d\left(x_{1}, x\right)\right) .
\end{aligned}
$$

So there exists some $x_{2} \in T x_{1}$ such that

$$
\begin{aligned}
& \lambda d\left(x_{0}, x_{1}\right) \\
& \quad+\frac{\mu d\left(x_{0}, S x_{0}\right) d\left(x_{1}, T x_{1}\right)+\gamma d\left(x_{1}, S x_{0}\right) d\left(x_{0}, T x_{1}\right)}{1+d\left(x_{0}, x_{1}\right)} \\
& \quad \in s\left(d\left(x_{1}, x_{2}\right)\right) .
\end{aligned}
$$

Therefore,

$$
\begin{aligned}
& d\left(x_{1}, x_{2}\right) \\
& \leq \lambda d\left(x_{0}, x_{1}\right) \\
& \quad+\frac{\mu d\left(x_{0}, S x_{0}\right) d\left(x_{1}, T x_{1}\right)+\gamma d\left(x_{1}, S x_{0}\right) d\left(x_{0}, T x_{1}\right)}{1+d\left(x_{0}, x_{1}\right)} .
\end{aligned}
$$

By using the greatest lower bound property (g.l.b property) of $S$ and $T$, we get

$$
\begin{aligned}
d\left(x_{1}, x_{2}\right) \leq & \lambda d\left(x_{0}, x_{1}\right) \\
& +\frac{\mu d\left(x_{0}, x_{1}\right) d\left(x_{1}, x_{2}\right)+\gamma d\left(x_{1}, x_{1}\right) d\left(x_{0}, x_{2}\right)}{1+d\left(x_{0}, x_{1}\right)} \\
= & \lambda d\left(x_{0}, x_{1}\right)+\frac{\mu d\left(x_{0}, x_{1}\right) d\left(x_{1}, x_{2}\right)}{1+d\left(x_{0}, x_{1}\right)},
\end{aligned}
$$

which implies that

$$
\begin{array}{r}
\left|d\left(x_{1}, x_{2}\right)\right| \leq \lambda\left|d\left(x_{0}, x_{1}\right)\right|+\frac{\mu\left|d\left(x_{0}, x_{1}\right)\right|\left|d\left(x_{1}, x_{2}\right)\right|}{\left|1+d\left(x_{0}, x_{1}\right)\right|} \\
=\lambda\left|d\left(x_{0}, x_{1}\right)\right|+\mu\left|d\left(x_{1}, x_{2}\right)\right|\left|\frac{d\left(x_{0}, x_{1}\right)}{1+d\left(x_{0}, x_{1}\right)}\right|, \\
\left|d\left(x_{1}, x_{2}\right)\right| \leq \lambda\left|d\left(x_{0}, x_{1}\right)\right|+\mu\left|d\left(x_{1}, x_{2}\right)\right|, \\
(1-\mu)\left|d\left(x_{1}, x_{2}\right)\right| \leq \lambda\left|d\left(x_{0}, x_{1}\right)\right|, \\
\left|d\left(x_{1}, x_{2}\right)\right| \leq \frac{\lambda}{(1-\mu)}\left|d\left(x_{0}, x_{1}\right)\right| \\
=h\left|d\left(x_{0}, x_{1}\right)\right|, \quad \text { where } h=\frac{\lambda}{(1-\mu)}<1 .
\end{array}
$$

Inductively, we can construct a sequence $\left\{x_{n}\right\}$ in $X$ such that for $n=0,1,2, \ldots$

$$
\left|d\left(x_{n}, x_{n+1}\right)\right| \leq h^{n}\left|d\left(x_{0}, x_{1}\right)\right|
$$

with $h=\lambda /(1-\mu)<1$, for $x_{2 n+1} \in S x_{2 n}$ and $x_{2 n+2} \in T x_{2 n+1}$. 
Now for $m>n$, we get

$$
\begin{aligned}
\left|d\left(x_{n}, x_{m}\right)\right| \leq & \left|d\left(x_{n}, x_{n+1}\right)\right|+\left|d\left(x_{n+1}, x_{n+2}\right)\right| \\
& +\cdots+\left|d\left(x_{m-1}, x_{m}\right)\right| \\
\leq & {\left[h^{n}+h^{n+1}+\cdots+h^{m-1}\right]\left|d\left(x_{0}, x_{1}\right)\right| } \\
\leq & {\left[\frac{h^{n}}{1-h}\right]\left|d\left(x_{0}, x_{1}\right)\right| . }
\end{aligned}
$$

Therefore,

$$
\left|d\left(x_{n}, x_{m}\right)\right| \leq \frac{h^{n}}{1-h}\left|d\left(x_{0}, x_{1}\right)\right| \longrightarrow 0 \quad \text { as } m, n \longrightarrow \infty
$$

This implies that $\left\{x_{n}\right\}$ is a Cauchy sequence in $X$. Since $X$ is complete, there exists $u \in X$ such that $x_{n} \rightarrow u$ as $n \rightarrow \infty$. We now show that $u \in T u$ and $u \in S u$. From (15), we have

$$
\begin{aligned}
& \lambda d\left(x_{2 k}, u\right) \\
& \quad+\frac{\mu d\left(x_{2 k}, S x_{2 k}\right) d(u, T u)+\gamma d\left(u, S x_{2 k}\right) d\left(x_{2 k}, T u\right)}{1+d\left(x_{2 k}, u\right)} \\
& \in s\left(S x_{2 k}, T u\right) .
\end{aligned}
$$

This implies that

$$
\begin{aligned}
& \lambda d\left(x_{2 k}, u\right) \\
& +\frac{\mu d\left(x_{2 k}, S x_{2 k}\right) d(u, T u)+\gamma d\left(u, S x_{2 k}\right) d\left(x_{2 k}, T u\right)}{1+d\left(x_{2 k}, u\right)} \\
& \quad \in\left(\bigcap_{\left.x \in S x_{2 k} s(x, T u)\right)},\right. \\
& \lambda d\left(x_{2 k}, u\right) \quad \forall \frac{\mu d\left(x_{2 k}, S x_{2 k}\right) d(u, T u)+\gamma d\left(u, S x_{2 k}\right) d\left(x_{2 k}, T u\right)}{1+d\left(x_{2 k}, u\right)} \\
& \quad \in \quad s(x, T u) \quad \forall x \in S x_{2 k} .
\end{aligned}
$$

Since $x_{2 k+1} \in S x_{2 k}$, we have

$$
\begin{aligned}
& \lambda d\left(x_{2 k}, u\right) \\
& \quad+\frac{\mu d\left(x_{2 k}, S x_{2 k}\right) d(u, T u)+\gamma d\left(u, S x_{2 k}\right) d\left(x_{2 k}, T u\right)}{1+d\left(x_{2 k}, u\right)} \\
& \in s\left(x_{2 k+1}, T u\right) .
\end{aligned}
$$

By definition,

$$
\begin{aligned}
& \lambda d\left(x_{2 k}, u\right) \\
& +\frac{\mu d\left(x_{2 k}, S x_{2 k}\right) d(u, T u)+\gamma d\left(u, S x_{2 k}\right) d\left(x_{2 k}, T u\right)}{1+d\left(x_{2 k}, u\right)} \\
& \in s\left(x_{2 k+1}, T u\right)=\bigcup_{u^{\prime} \in T u} s\left(d\left(x_{2 k+1}, u^{\prime}\right)\right) .
\end{aligned}
$$

There exists some $u_{k} \in T u$ such that

$$
\begin{aligned}
& \lambda d\left(x_{2 k}, u\right) \\
& \quad+\frac{\mu d\left(x_{2 k}, S x_{2 k}\right) d(u, T u)+\gamma d\left(u, S x_{2 k}\right) d\left(x_{2 k}, T u\right)}{1+d\left(x_{2 k}, u\right)} \\
& \in s\left(d\left(x_{2 k+1}, u_{k}\right)\right) ;
\end{aligned}
$$

that is,

$$
\begin{aligned}
& d\left(x_{2 k+1}, u_{k}\right) \\
& \leq \lambda d\left(x_{2 k}, u\right) \\
& \quad+\frac{\mu d\left(x_{2 k}, S x_{2 k}\right) d(u, T u)+\gamma d\left(u, S x_{2 k}\right) d\left(x_{2 k}, T u\right)}{1+d\left(x_{2 k}, u\right)} .
\end{aligned}
$$

By using the greatest lower bound property (g.l.b. property) of $S$ and $T$, we have

$$
\begin{aligned}
& d\left(x_{2 k+1}, u_{k}\right) \\
& \preceq \lambda d\left(x_{2 k}, u\right)+\left(\mu d\left(x_{2 k}, x_{2 k+1}\right) d\left(u, u_{k}\right)\right. \\
& \left.\quad+\gamma d\left(u, x_{2 k+1}\right) d\left(x_{2 k}, u_{k}\right)\right)\left(1+d\left(x_{2 k}, u\right)\right)^{-1} .
\end{aligned}
$$

Since

$$
d\left(u, u_{k}\right) \preceq d\left(u, x_{2 k+1}\right)+d\left(x_{2 k+1}, u_{k}\right),
$$

using (32), we get

$$
\begin{aligned}
& d\left(u, u_{k}\right) \\
& \leq d\left(u, x_{2 k+1}\right)+\lambda d\left(u, x_{2 k+1}\right) \\
& \quad+\frac{\mu d\left(x_{2 k}, x_{2 k+1}\right) d\left(u, u_{k}\right)+\gamma d\left(u, x_{2 k+1}\right) d\left(x_{2 k}, u_{k}\right)}{1+d\left(x_{2 k}, u\right)} \\
& \quad\left|d\left(u, u_{k}\right)\right| \\
& \leq\left|d\left(u, x_{2 k+1}\right)\right|+\lambda\left|d\left(u, x_{2 k+1}\right)\right| \\
& \quad+\left(\mu\left|d\left(x_{2 k}, x_{2 k+1}\right)\right|\left|d\left(u, u_{k}\right)\right|\right. \\
& \left.\quad+\gamma\left|d\left(u, x_{2 k+1}\right)\right|\left|d\left(x_{2 k}, u_{k}\right)\right|\right) \\
& \quad \times\left|1+d\left(x_{2 k}, u\right)\right|^{-1} .
\end{aligned}
$$


Taking the limit as $k \rightarrow \infty$, we get $\left|d\left(u, u_{k}\right)\right| \rightarrow 0$ as $k \rightarrow$ $\infty$. By [9, lemma 2], we have $u_{k} \rightarrow u$ as $k \rightarrow \infty$. Since Tu is closed, $u \in T u$. Similarly, it follows that $u \in S u$. Thus, $S$ and $T$ have a common fixed point.

By setting $\gamma=0$ in Theorem 9, we get the following corollary.

Corollary 10. Let $(X, d)$ be a complete complex valued metric space and let $S, T: X \rightarrow C B(X)$ be multivalued mappings with g.l.b property such that

$$
\lambda d(x, y)+\mu \frac{d(x, S x) d(y, T y)}{1+d(x, y)} \in s(S x, T y)
$$

for all $x, y \in X$ and $\lambda, \mu$ are nonnegative real numbers with $\lambda+\mu<1$. Then $S, T$ have a common fixed point.

By setting $S=T$ in Theorem 9, we get the following Corollary.

Corollary 11. Let $(X, d)$ be a complete complex valued metric space and let $T: X \rightarrow C B(X)$ be multivalued mapping with g.l.b property such that

$$
\begin{aligned}
& \lambda d(x, y)+\frac{\mu d(x, T x) d(y, T y)+\gamma d(y, T x) d(x, T y)}{1+d(x, y)} \\
& \quad \in s(T x, T y)
\end{aligned}
$$

for all $x, y \in X$ and $\lambda, \mu$, and $\gamma$ are nonnegative real numbers with $\lambda+\mu+\gamma<1$. Then $T$ has a fixed point in $X$.

By Remark 4, we have the following corollaries from Theorem 9.

Corollary 12. Let $(X, d)$ be a complete metric space and let $S, T: X \rightarrow C B(X)$ be multivalued mappings such that

$$
\begin{aligned}
H(S x, T y) \leq & \lambda d(x, y) \\
& +\frac{\mu d(x, S x) d(y, T y)+\gamma d(y, S x) d(x, T y)}{1+d(x, y)}
\end{aligned}
$$

for all $x, y \in X$ and $\lambda$, $\mu$, and $\gamma$ are nonnegative real numbers with $\lambda+\mu+\gamma<1$. Then $S, T$ have a common fixed point.

Remark 13. By equating $\lambda, \mu, \gamma$ to 0 in all possible combinations, one can derive a host of corollaries which include the Banach fixed point theorem for multivalued mappings in complete metric space.

Example 14. Let $X=[0,1]$. Define $d: X \times X \rightarrow \mathbb{C}$ by

$$
d(x, y)=|x-y| e^{i \theta}, \quad \theta=\tan ^{-1}\left|\frac{y}{x}\right| .
$$

Then $(X, d)$ is a complex valued metric space. Consider the mappings $S, T: X \rightarrow C B(X)$ defined by

$$
S x=\left[0, \frac{1}{5} x\right], \quad T x=\left[0, \frac{1}{10} x\right] .
$$

The contractive condition of main theorem is trivial for the case when $x=y=0$. Suppose without any loss of generality that all $x, y$ are nonzero and $x<y$. Then

$$
\begin{aligned}
d(x, y) & =|y-x| e^{i \theta}, \\
d(x, S x) & =\left|x-\frac{x}{5}\right| e^{i \theta}, \\
d(y, T y) & =\left|y-\frac{y}{10}\right| e^{i \theta}, \\
d(y, S x) & =\left|y-\frac{x}{5}\right| e^{i \theta}, \\
d(x, T y) & =\left|x-\frac{y}{10}\right| e^{i \theta}, \\
s(S x, T y)=s & \left(\left|\frac{x}{5}-\frac{y}{10}\right| e^{i \theta}\right) .
\end{aligned}
$$

Consider,

$$
\begin{aligned}
\lambda|d(x, y)|+\frac{\mu|d(x, S x)||d(y, T y)|+\gamma|d(y, S x)||d(x, T y)|}{|1+d(x, y)|} \\
=\lambda|y-x| \\
\quad+\frac{\mu|x-(x / 5)||y-(y / 10)|+\gamma|y-(x / 5)||x-(y / 10)|}{|1+d(x, y)|} \\
=\lambda|y-x| \\
\quad+\frac{\mu|x-(x / 5)||y-(y / 10)|+\gamma|y-(x / 5)||x-(y / 10)|}{|1+d(x, y)|} .
\end{aligned}
$$

Clearly, for any value of $\mu$ and $\gamma$ and $\lambda=1 / 5$, we have

$$
\begin{aligned}
\left|\frac{x}{5}-\frac{y}{10}\right| & \\
\leq & \frac{1}{5}|y-x| \\
& +\frac{\mu|x-(x / 5)||y-(y / 10)|+\gamma|y-(x / 5)||x-(y / 10)|}{|1+d(x, y)|} .
\end{aligned}
$$

Thus,

$$
\begin{aligned}
& \lambda d(x, y)+\frac{\mu d(x, S x) d(y, T y)+\gamma d(y, S x) d(x, T y)}{1+d(x, y)} \\
& \quad \in s(S x, T y) .
\end{aligned}
$$

Hence, all the conditions of our main theorem are satisfied and 0 is a common fixed point of $S$ and $T$. 
In the following results, we considered the Kannan type contractive condition involving rational expressions.

Theorem 15. Let $(X, d)$ be a complete complex valued metric space and let $S, T: X \rightarrow C B(X)$ be multivalued mappings with g.l.b property such that

$$
a d(x, S x)+b d(y, T y)+c \frac{d(x, S x) d(y, T y)}{1+d(x, y)} \in s(S x, T y)
$$

for all $x, y \in X$ and $a+b+c<1$. Then $S$ and $T$ have a common fixed point.

Proof. Let $x_{0} \in X$ and $x_{1} \in S x_{0}$. From (44), we get

$$
\begin{aligned}
& a d\left(x_{0}, S x_{0}\right)+b d\left(x_{1}, T x_{1}\right)+c \frac{d\left(x_{0}, S x_{0}\right) d\left(x_{1}, T x_{1}\right)}{1+d\left(x_{0}, x_{1}\right)} \\
& \quad \in s\left(S x_{0}, T x_{1}\right) .
\end{aligned}
$$

This implies that

$$
\begin{aligned}
& a d\left(x_{0}, S x_{0}\right)+b d\left(x_{1}, T x_{1}\right)+c \frac{d\left(x_{0}, S x_{0}\right) d\left(x_{1}, T x_{1}\right)}{1+d\left(x_{0}, x_{1}\right)} \\
& \in\left(\bigcap_{x \in S x_{0}} s\left(x, T x_{1}\right)\right), \\
& a d\left(x_{0}, S x_{0}\right)+b d\left(x_{1}, T x_{1}\right)+c \frac{d\left(x_{0}, S x_{0}\right) d\left(x_{1}, T x_{1}\right)}{1+d\left(x_{0}, x_{1}\right)} \\
& \quad \in s\left(x, T x_{1}\right) \quad \forall x \in S x_{0} .
\end{aligned}
$$

Since $x_{1} \in S x_{0}$, we have

$$
\begin{aligned}
& a d\left(x_{0}, S x_{0}\right)+b d\left(x_{1}, T x_{1}\right)+c \frac{d\left(x_{0}, S x_{0}\right) d\left(x_{1}, T x_{1}\right)}{1+d\left(x_{0}, x_{1}\right)} \\
& \quad \in s\left(x_{1}, T x_{1}\right), \\
& a d\left(x_{0}, S x_{0}\right)+b d\left(x_{1}, T x_{1}\right)+c \frac{d\left(x_{0}, S x_{0}\right) d\left(x_{1}, T x_{1}\right)}{1+d\left(x_{0}, x_{1}\right)} \\
& \quad \in s\left(x_{1}, T x_{1}\right)=\bigcup_{x \in T x_{1}} s\left(d\left(x_{1}, x\right)\right) .
\end{aligned}
$$

So there exists some $x_{2} \in T x_{1}$, such that

$$
\begin{aligned}
& a d\left(x_{0}, S x_{0}\right)+b d\left(x_{1}, T x_{1}\right)+c \frac{d\left(x_{0}, S x_{0}\right) d\left(x_{1}, T x_{1}\right)}{1+d\left(x_{0}, x_{1}\right)} \\
& \quad \in s\left(d\left(x_{1}, x_{2}\right)\right) .
\end{aligned}
$$

That is,

$$
\begin{aligned}
d\left(x_{1}, x_{2}\right) \leq & a d\left(x_{0}, S x_{0}\right)+b d\left(x_{1}, T x_{1}\right) \\
& +c \frac{d\left(x_{0}, S x_{0}\right) d\left(x_{1}, T x_{1}\right)}{1+d\left(x_{0}, x_{1}\right)} .
\end{aligned}
$$

By using the greatest lower bound property (g.l.b property) of $S$ and $T$, we get

$d\left(x_{1}, x_{2}\right) \preceq a d\left(x_{0}, x_{1}\right)+b d\left(x_{1}, x_{2}\right)+c \frac{d\left(x_{0}, x_{1}\right) d\left(x_{1}, x_{2}\right)}{1+d\left(x_{0}, x_{1}\right)}$

which implies that

$$
\begin{aligned}
\left|d\left(x_{1}, x_{2}\right)\right| \leq & a\left|d\left(x_{0}, x_{1}\right)\right|+b\left|d\left(x_{1}, x_{2}\right)\right| \\
& +c \frac{\left|d\left(x_{0}, x_{1}\right)\right|\left|d\left(x_{1}, x_{2}\right)\right|}{\left|1+d\left(x_{0}, x_{1}\right)\right|} .
\end{aligned}
$$

Since $\left|d\left(x_{0}, x_{1}\right)\right|<\left|1+d\left(x_{0}, x_{1}\right)\right|$, we have

$$
\begin{gathered}
\left|d\left(x_{1}, x_{2}\right)\right| \leq a\left|d\left(x_{0}, x_{1}\right)\right|+b\left|d\left(x_{1}, x_{2}\right)\right|+c\left|d\left(x_{1}, x_{2}\right)\right|, \\
(1-b-c)\left|d\left(x_{1}, x_{2}\right)\right| \leq a\left|d\left(x_{0}, x_{1}\right)\right| \\
\left|d\left(x_{1}, x_{2}\right)\right| \leq \frac{a}{(1-b-c)}\left|d\left(x_{0}, x_{1}\right)\right| .
\end{gathered}
$$

Thus,

$$
\begin{aligned}
\left|d\left(x_{1}, x_{2}\right)\right| & \leq \frac{a}{(1-b-c)}\left|d\left(x_{0}, x_{1}\right)\right| \\
& =l\left|d\left(x_{0}, x_{1}\right)\right|, \quad \text { where } l=\frac{a}{(1-b-c)}<1 .
\end{aligned}
$$

Inductively, we can construct a sequence $\left\{x_{n}\right\}$ in $X$ such that for $n=0,1,2, \ldots$

$$
\left|d\left(x_{n}, x_{n+1}\right)\right| \leq l^{n}\left|d\left(x_{0}, x_{1}\right)\right|
$$

with $l=a /(1-b-c)<1$, for $x_{2 n+1} \in S x_{2 n}$ and $x_{2 n+2} \in T x_{2 n+1}$. Now for $m>n$, we get

$$
\begin{aligned}
\left|d\left(x_{n}, x_{m}\right)\right| \leq & \left|d\left(x_{n}, x_{n+1}\right)\right|+\left|d\left(x_{n+1}, x_{n+2}\right)\right| \\
& +\cdots+\left|d\left(x_{m-1}, x_{m}\right)\right| \\
\leq & {\left[l^{n}+l^{n+1}+\cdots+l^{m-1}\right]\left|d\left(x_{0}, x_{1}\right)\right| } \\
\leq & {\left[\frac{l^{n}}{1-l}\right]\left|d\left(x_{0}, x_{1}\right)\right|, }
\end{aligned}
$$

and so

$$
\left|d\left(x_{n}, x_{m}\right)\right| \leq \frac{l^{n}}{1-l}\left|d\left(x_{0}, x_{1}\right)\right| \longrightarrow 0 \quad \text { as } m, n \rightarrow \infty .
$$

This implies that $\left\{x_{n}\right\}$ is a Cauchy sequence in $X$. Since $X$ is complete, there exists $v \in X$ such that $x_{n} \rightarrow v$ as $n \rightarrow \infty$. We now show that $v \in T v$ and $v \in S v$. So from (44), we get

$$
\begin{aligned}
& a d\left(x_{2 n}, S x_{2 n}\right)+b d(v, T v)+c \frac{d\left(x_{2 n}, S x_{2 n}\right) d(v, T v)}{1+d\left(x_{2 n}, v\right)} \\
& \quad \in s\left(S x_{2 n}, T v\right) .
\end{aligned}
$$


This implies that

$$
\begin{aligned}
& a d\left(x_{2 n}, S x_{2 n}\right)+b d(v, T v)+c \frac{d\left(x_{2 n}, S x_{2 n}\right) d(v, T v)}{1+d\left(x_{2 n}, v\right)} \\
& \in\left(\bigcap_{x \in S x_{2 n}} s(x, T v)\right), \\
& a d\left(x_{2 n}, S x_{2 n}\right)+b d(v, T v)+c \frac{d\left(x_{2 n}, S x_{2 n}\right) d(v, T v)}{1+d\left(x_{2 n}, v\right)} \\
& \quad \in s(x, T v) \quad \forall x \in S x_{2 n} .
\end{aligned}
$$

Since $x_{2 n+1} \in S x_{2 n}$, we have

$$
\begin{aligned}
& a d\left(x_{2 n}, S x_{2 n}\right)+b d(v, T v)+c \frac{d\left(x_{2 n}, S x_{2 n}\right) d(v, T v)}{1+d\left(x_{2 n}, v\right)} \\
& \quad \in s\left(x_{2 n+1}, T v\right) .
\end{aligned}
$$

By definition,

$$
\begin{aligned}
& \operatorname{ad}\left(x_{2 n}, S x_{2 n}\right)+b d(v, T v)+c \frac{d\left(x_{2 n}, S x_{2 n}\right) d(v, T v)}{1+d\left(x_{2 n}, v\right)} \\
& \in s\left(x_{2 n+1}, T v\right)=\bigcup_{v^{\prime} \in T v} s\left(d\left(x_{2 n+1}, v^{\prime}\right)\right) .
\end{aligned}
$$

There exists some $v_{n} \in T v$ such that

$$
\begin{aligned}
& a d\left(x_{2 n}, S x_{2 n}\right)+b d(v, T v)+c \frac{d\left(x_{2 n}, S x_{2 n}\right) d(v, T v)}{1+d\left(x_{2 n}, v\right)} \\
& \quad \in s\left(d\left(x_{2 n+1}, v_{n}\right)\right)
\end{aligned}
$$

that is,

$$
\begin{aligned}
d\left(x_{2 n+1}, v_{n}\right) \preceq & a d\left(x_{2 n}, S x_{2 n}\right)+b d(v, T v) \\
& +c \frac{d\left(x_{2 n}, S x_{2 n}\right) d(v, T v)}{1+d\left(x_{2 n}, v\right)} .
\end{aligned}
$$

By using the greatest lower bound property (g.l.b property) of $S$ and $T$, we get

$$
\begin{aligned}
d\left(x_{2 n+1}, v_{n}\right) \leq & a d\left(x_{2 n}, x_{2 n+1}\right)+b d\left(v, v_{n}\right) \\
& +c \frac{d\left(x_{2 n}, x_{2 n+1}\right) d\left(v, v_{n}\right)}{1+d\left(x_{2 n}, v\right)} .
\end{aligned}
$$

Now by using the triangular inequality, we get

$$
\begin{aligned}
d\left(v, v_{n}\right) \preceq & d\left(v, x_{2 n+1}\right)+d\left(x_{2 n+1}, v_{n}\right) \\
\preceq & d\left(v, x_{2 n+1}\right)+a d\left(x_{2 n}, x_{2 n+1}\right) \\
& +b d\left(v, v_{n}\right)+c \frac{d\left(x_{2 n}, x_{2 n+1}\right) d\left(v, v_{n}\right)}{1+d\left(x_{2 n}, v\right)} .
\end{aligned}
$$

That is,

$$
\begin{aligned}
(1-b)\left|d\left(v, v_{n}\right)\right| \leq & \left|d\left(v, x_{2 n+1}\right)\right|+a\left|d\left(x_{2 n}, x_{2 n+1}\right)\right| \\
& +c\left|\frac{d\left(x_{2 n}, x_{2 n+1}\right) d\left(v, v_{n}\right)}{1+d\left(x_{2 n}, v\right)}\right| .
\end{aligned}
$$

It follows that

$$
\begin{aligned}
\left|d\left(v, v_{n}\right)\right| \leq & \frac{1}{(1-b)}\left|d\left(v, x_{2 n+1}\right)\right|+\frac{a}{(1-b)}\left|d\left(x_{2 n}, x_{2 n+1}\right)\right| \\
& +\frac{c}{(1-b)} \frac{\left|d\left(x_{2 n}, x_{2 n+1}\right)\right|\left|d\left(v, v_{n}\right)\right|}{\left|1+d\left(x_{2 n}, v\right)\right|} .
\end{aligned}
$$

By letting $n \rightarrow \infty$ in the above inequality, we get

$$
\left|d\left(v, v_{n}\right)\right| \longrightarrow 0 \quad \text { as } n \longrightarrow \infty \text {. }
$$

By [9, Lemma 2], we have $v_{n} \rightarrow v$ as $n \rightarrow \infty$. Since $T v$ is closed, $v \in T v$. Similarly, it follows that $v \in S v$. Thus, $S$ and $T$ have a common fixed point.

Corollary 16. Let $(X, d)$ be a complete complex valued metric space and let $S, T: X \rightarrow C B(X)$ be multivalued mappings with g.l.b property such that

$$
\alpha(d(x, S x)+d(y, T y)) \in s(S x, T y)
$$

for all $x, y \in X$ and $0 \leq \alpha<1 / 2$. Then $S$ and $T$ have a common fixed point.

By setting $S=T$ in Theorem 15, we get the following corollary.

Corollary 17. Let $(X, d)$ be a complete complex valued metric space and let $T: X \rightarrow C B(X)$ be multivalued mappings with g.l.b property such that

$$
a d(x, T x)+b d(y, T y)+c \frac{d(x, T x) d(y, T y)}{1+d(x, y)} \in s(T x, T y)
$$

for all $x, y \in X$ and $a+b+c<1$. Then $T$ has a fixed point.

By Remark 4 we have the following corollaries.

Corollary 18. Let $(X, d)$ be a complete metric space and let $S, T: X \rightarrow C B(X)$ be multivalued mappings such that

$$
H(S x, T y) \leq a d(x, S x)+b d(y, T y)+c \frac{d(x, S x) d(y, T y)}{1+d(x, y)}
$$

for all $x, y \in X$ and $a, b$, and $c$ are nonnegative real numbers with $a+b+c<1$. Then $S, T$ have a common fixed point.

Remark 19. By writing $a, b, c$ in all possible combinations, one can derive a host of corollaries which include the Kannan fixed point theorem for multivalued mappings in complete metric space. 
In the following results, we considered the Chatterjea type locally contractive condition involving rational expressions.

Theorem 20. Let $S, T: X \rightarrow C B(X)$ be multivalued mappings with the g.l.b property on complete complex valued metric space $(X, d), x_{0} \in X$, and $0 \prec r \in \mathbb{C}$. IfS and $T$ satisfy

$a d(y, S x)+b d(x, T y)+c\left[\frac{d(y, S x) d(x, T y)}{1+d(x, y)}\right] \in s(S x, T y)$

for all $x, y \in \bar{B}\left(x_{0}, r\right)$ and

$$
(1-k) r \in s\left(x_{0}, S x_{0}\right),
$$

where $a, b$, and $c$ are nonnegative real numbers with $k=b /(1-$ $b)<1$, then $S$ and $T$ have a common fixed point in $\bar{B}\left(x_{0}, r\right)$.

Proof. Let $x_{0}$ be an arbitrary point in $X$. From (72), one can easily prove that

$$
\left|d\left(x_{0}, x_{1}\right)\right| \leq(1-k)|r| .
$$

Thus, we have $x_{1} \in \bar{B}\left(x_{0}, r\right)$. From (71), we get

$$
\begin{aligned}
& a d\left(x_{1}, S x_{0}\right)+b d\left(x_{0}, T x_{1}\right)+c\left[\frac{d\left(x_{1}, S x_{0}\right) d\left(x_{0}, T x_{1}\right)}{1+d\left(x_{0}, x_{1}\right)}\right] \\
& \quad \in s\left(S x_{0}, T x_{1}\right) .
\end{aligned}
$$

This implies that

$$
\begin{aligned}
& a d\left(x_{1}, S x_{0}\right)+b d\left(x_{0}, T x_{1}\right)+c\left[\frac{d\left(x_{1}, S x_{0}\right) d\left(x_{0}, T x_{1}\right)}{1+d\left(x_{0}, x_{1}\right)}\right] \\
& \quad \in s\left(x_{1}, T x_{1}\right) .
\end{aligned}
$$

By the definition, we can take $x_{2} \in T x_{1}$ such that

$$
\begin{aligned}
& a d\left(x_{1}, S x_{0}\right)+b d\left(x_{0}, T x_{1}\right)+c\left[\frac{d\left(x_{1}, S x_{0}\right) d\left(x_{0}, T x_{1}\right)}{1+d\left(x_{0}, x_{1}\right)}\right] \\
& \quad \in s\left(d\left(x_{1}, x_{2}\right)\right) .
\end{aligned}
$$

By the definition, we get

$$
\begin{aligned}
d\left(x_{1}, x_{2}\right) \leq & a d\left(x_{1}, S x_{0}\right)+b d\left(x_{0}, T x_{1}\right) \\
& +c\left[\frac{d\left(x_{1}, S x_{0}\right) d\left(x_{0}, T x_{1}\right)}{1+d\left(x_{0}, x_{1}\right)}\right] .
\end{aligned}
$$

By using the g.l.b property of $S$ and $T$, we get

$$
\begin{aligned}
d\left(x_{1}, x_{2}\right) \leq & a d\left(x_{1}, x_{1}\right)+b d\left(x_{0}, x_{2}\right) \\
& +c\left[\frac{d\left(x_{1}, x_{1}\right) d\left(x_{0}, x_{2}\right)}{1+d\left(x_{0}, x_{1}\right)}\right] .
\end{aligned}
$$

Hence, we have

$$
d\left(x_{1}, x_{2}\right) \preceq b d\left(x_{0}, x_{2}\right)
$$

which implies that

$$
\left|d\left(x_{1}, x_{2}\right)\right| \leq k\left|d\left(x_{0}, x_{1}\right)\right|,
$$

where $k=b /(1-b)<1$. From (73), we get

$$
\left|d\left(x_{1}, x_{2}\right)\right| \leq k(1-k)|r| \text {. }
$$

Note that

$$
\begin{aligned}
\left|d\left(x_{0}, x_{2}\right)\right| & \leq\left|d\left(x_{0}, x_{1}\right)\right|+\left|d\left(x_{1}, x_{2}\right)\right| \\
& \leq(1-k)|r|+k(1-k)|r| \\
& =(1-k)(1+k)|r| \\
& \leq\left(1-k^{2}\right)|r| .
\end{aligned}
$$

Thus, we have $x_{2} \in \bar{B}\left(x_{0}, r\right)$. From (71), we get

$$
\begin{aligned}
& a d\left(x_{2}, T x_{1}\right)+b d\left(x_{1}, S x_{2}\right)+\left[c \frac{d\left(x_{2}, T x_{1}\right) d\left(x_{1}, S x_{2}\right)}{1+d\left(x_{1}, x_{2}\right)}\right] \\
& \quad \in s\left(T x_{1}, S x_{2}\right) .
\end{aligned}
$$

This implies that

$$
\begin{aligned}
& a d\left(x_{2}, T x_{1}\right)+b d\left(x_{1}, S x_{2}\right)+\left[c \frac{d\left(x_{2}, T x_{1}\right) d\left(x_{1}, S x_{2}\right)}{1+d\left(x_{1}, x_{2}\right)}\right] \\
& \quad \in s\left(x_{2}, S x_{2}\right) .
\end{aligned}
$$

By the definition, there exists $x_{3} \in S x_{2}$ such that

$$
\begin{aligned}
& a d\left(x_{2}, T x_{1}\right)+b d\left(x_{1}, S x_{2}\right)+\left[c \frac{d\left(x_{2}, T x_{1}\right) d\left(x_{1}, S x_{2}\right)}{1+d\left(x_{1}, x_{2}\right)}\right] \\
& \quad \in s\left(d\left(x_{2}, x_{3}\right)\right) .
\end{aligned}
$$

By the definition, we get

$$
\begin{aligned}
d\left(x_{2}, x_{3}\right) \leq & a d\left(x_{2}, T x_{1}\right)+b d\left(x_{1}, S x_{2}\right) \\
& +\left[c \frac{d\left(x_{2}, T x_{1}\right) d\left(x_{1}, S x_{2}\right)}{1+d\left(x_{1}, x_{2}\right)}\right] .
\end{aligned}
$$

By using the g.l.b property of $S$ and $T$, we get

$$
\begin{aligned}
d\left(x_{2}, x_{3}\right) \leq & a d\left(x_{2}, x_{2}\right)+b d\left(x_{1}, x_{3}\right) \\
& +\left[c \frac{d\left(x_{2}, x_{2}\right) d\left(x_{1}, x_{3}\right)}{1+d\left(x_{1}, x_{2}\right)}\right] .
\end{aligned}
$$

Hence, we have

$$
d\left(x_{2}, x_{3}\right) \preceq b d\left(x_{1}, x_{3}\right)
$$


which implies that

$$
\left|d\left(x_{2}, x_{3}\right)\right| \leq k\left|d\left(x_{1}, x_{2}\right)\right|
$$

where $k=b /(1-b)<1$. Consider that

$$
\begin{aligned}
\left|d\left(x_{0}, x_{3}\right)\right| & \leq\left|d\left(x_{0}, x_{1}\right)\right|+\left|d\left(x_{1}, x_{2}\right)\right|+\left|d\left(x_{2}, x_{3}\right)\right| \\
& \leq(1-k)|r|+k(1-k)|r|+k^{2}(1-k)|r| \\
& =\left(1-k^{3}\right)|r| \leq|r| .
\end{aligned}
$$

So $x_{3} \in \bar{B}\left(x_{0}, r\right)$. Continuing in this way, we can construct a sequence $\left\{x_{n}\right\}$ in $\bar{B}\left(x_{0}, r\right)$ such that for each $n \geq 1$,

$$
\begin{gathered}
\left|d\left(x_{2 n}, x_{2 n+1}\right)\right| \leq k^{2 n}\left|d\left(x_{0}, x_{1}\right)\right|, \\
\left|d\left(x_{2 n+1}, x_{2 n+2}\right)\right| \leq k^{2 n+1}\left|d\left(x_{0}, x_{1}\right)\right|,
\end{gathered}
$$

where $k=b /(1-b)<1, x_{2 n+1} \in S x_{2 n}$, and $x_{2 n+2} \in T x_{2 n+1}$. Now, inductively, we can construct a sequence $\left\{x_{n}\right\}$ in $X$ such that for each $n \geq 0$,

$$
\left|d\left(x_{n}, x_{n+1}\right)\right| \leq k^{n}\left|d\left(x_{0}, x_{1}\right)\right| .
$$

Thus, as in the proof of Theorem $15,\left\{x_{n}\right\}$ is a Cauchy sequence in $\bar{B}\left(x_{0}, r\right)$. Since $X$ is complete and $\bar{B}\left(x_{0}, r\right)$ is a closed subspace of $X$, there exists $v \in \bar{B}\left(x_{0}, r\right)$ such that $x_{n} \rightarrow u$ as $n \rightarrow \infty$. Now, we show that $v \in T v$ and $v \in S v$. From (71), we get

$$
\begin{aligned}
& a d\left(v, S x_{2 n}\right)+b d\left(x_{2 n}, T v\right)+c\left[\frac{d\left(v, S x_{2 n}\right) d\left(x_{2 n}, T v\right)}{1+d\left(x_{2 n}, v\right)}\right] \\
& \quad \in s\left(S x_{2 n}, T v\right) .
\end{aligned}
$$

This implies that

$$
\begin{aligned}
& a d\left(v, S x_{2 n}\right)+b d\left(x_{2 n}, T v\right)+c\left[\frac{d\left(v, S x_{2 n}\right) d\left(x_{2 n}, T v\right)}{1+d\left(x_{2 n}, v\right)}\right] \\
& \quad \in s\left(x_{2 n+1}, T v\right) .
\end{aligned}
$$

By the definition, there exists $v_{n} \in T v$ such that

$$
\begin{aligned}
& a d\left(v, S x_{2 n}\right)+b d\left(x_{2 n}, T v\right)+c\left[\frac{d\left(v, S x_{2 n}\right) d\left(x_{2 n}, T v\right)}{1+d\left(x_{2 n}, v\right)}\right] \\
& \quad \in s\left(d\left(x_{2 n+1}, v_{n}\right)\right) .
\end{aligned}
$$

By the definition, we get

$$
\begin{aligned}
d\left(x_{2 n+1}, v_{n}\right) \preceq & a d\left(v, S x_{2 n}\right)+b d\left(x_{2 n}, T v\right) \\
& +c\left[\frac{d\left(v, S x_{2 n}\right) d\left(x_{2 n}, T v\right)}{1+d\left(x_{2 n}, v\right)}\right]
\end{aligned}
$$

By using the g.l.b property of $S$ and $T$, we get

$$
\begin{aligned}
d\left(x_{2 n+1}, v_{n}\right) \leq & a d\left(v, x_{2 n+1}\right)+b d\left(x_{2 n}, v_{n}\right) \\
& +c\left[\frac{d\left(v, x_{2 n+1}\right) d\left(x_{2 n}, v_{n}\right)}{1+d\left(x_{2 n}, v\right)}\right] .
\end{aligned}
$$

Hence, we have

$$
\begin{aligned}
0 \prec d\left(x_{2 n+1}, v_{n}\right) \preceq & a d\left(v, x_{2 n+1}\right)+b d\left(x_{2 n}, v_{n}\right) \\
& +c\left[\frac{d\left(v, x_{2 n+1}\right) d\left(x_{2 n}, v_{n}\right)}{1+d\left(x_{2 n}, v\right)}\right] .
\end{aligned}
$$

Now, by using the triangular inequality, we get

$$
\begin{aligned}
d\left(v, v_{n}\right) & \leq d\left(v, x_{2 n+1}\right)+d\left(x_{2 n+1}, v_{n}\right) \\
& \preceq d\left(v, x_{2 n+1}\right)+a d\left(v, x_{2 n+1}\right)+b d\left(x_{2 n}, v_{n}\right) \\
& +c\left[\frac{d\left(v, x_{2 n+1}\right) d\left(x_{2 n}, v_{n}\right)}{1+d\left(x_{2 n}, v\right)}\right],
\end{aligned}
$$

and so

$$
\begin{aligned}
\left|d\left(v, v_{n}\right)\right| \leq & \left|d\left(v, x_{2 n+1}\right)\right|+a\left|d\left(v, x_{2 n+1}\right)\right| \\
& +b\left|d\left(x_{2 n}, v_{n}\right)\right|+c\left[\left|\frac{d\left(v, x_{2 n+1}\right) d\left(x_{2 n}, v_{n}\right)}{1+d\left(x_{2 n}, v\right)}\right|\right] .
\end{aligned}
$$

Byletting $n \rightarrow \infty$ in the above inequality, we get $\left|d\left(v, v_{n}\right)\right| \rightarrow$ 0 as $n \rightarrow \infty$. By [9, Lemma 2.2], it follows that $v_{n} \rightarrow v$ as $n \rightarrow \infty$. Since $T v$ is closed, $v \in T v$. Similarly, it follows that $v \in S v$. Thus, $S$ and $T$ have a common fixed point in $X$. This completes the proof.

By taking $c=0$ in Theorem 20, we get the following Corollary.

Corollary 21. Let $S, T: X \rightarrow C B(X)$ be multivalued mappings with the g.l.b property in complete complex valued metric space $(X, d), x_{0} \in X$, and $0 \prec r \in \mathbb{C}$. If $S$ and $T$ satisfy

$$
a d(y, S x)+b d(x, T y) \in s(S x, T y)
$$

for all $x, y \in \bar{B}\left(x_{0}, r\right)$ and

$$
(1-k) r \in s\left(x_{0}, S x_{0}\right)
$$

where $a$ and $b$ are nonnegative real numbers with $k=b /(1-$ $b)<1$, then $S$ and $T$ have a common fixed point in $\bar{B}\left(x_{0}, r\right)$.

By taking $S=T$ in Theorem 20, we get the following.

Corollary 22. Let $T: X \rightarrow C B(X)$ be multivalued mapping with the g.l.b property in complete complex valued metric space $(X, d), x_{0} \in X$, and $0 \prec r \in \mathbb{C}$. If $T$ satisfies

$$
a d(y, T x)+b d(x, T y)+c\left[\frac{d(y, T x) d(x, T y)}{1+d(x, y)}\right] \in s(T x, T y)
$$


for all $x, y \in \bar{B}\left(x_{0}, r\right)$ and

$$
(1-k) r \in s\left(x_{0}, T x_{0}\right),
$$

where $a, b$, and $c$ are nonnegative real numbers with $k=b /(1-$ $b)<1$, then $T$ has a fixed point in $\bar{B}\left(x_{0}, r\right)$.

\section{Applications}

As an application of the main result (Corollary 22), we prove the following homotopy result.

Theorem 23. Let $(X, d)$ be a complete complex valued metric space and let $U$ be an open subset of $X$. Let $F:[0,1] \times \bar{U} \rightarrow$ $C B(X)$ be multivalued mapping with the g.l.b property. Suppose that there exist $\dot{\zeta} \in X$ and $0 \prec r \in \mathbb{C}$ such that

(a) $\zeta \notin[F(t, \zeta)]$ for all $\zeta \in \partial U$ and $t \in[0,1]$;

(b) $F(t, \cdot): \bar{U} \rightarrow C B(X)$ is a multivalued mapping satisfying

$$
\begin{aligned}
& a d(\dot{\zeta}, F(t, \zeta))+b d(\zeta, F(\dot{t}, \dot{\zeta}))
\end{aligned}
$$

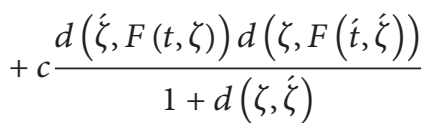

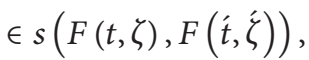

$$
\begin{aligned}
& (1-k) r \in s(\dot{\zeta}, F(\stackrel{\circ}{t}, \dot{\zeta})),
\end{aligned}
$$

where $k=b /(1-b)<1$;

(c) there exists a continuous increasing function $\varphi$ : $(0,1] \rightarrow P \cup\{0\}$ such that

$$
\varphi(s)-\varphi(t) \in s(F(s, \zeta), F(t, \zeta)), \quad \varphi(s) \in \varphi(t)
$$

for all $s, t \in[0,1]$ and $\zeta \in \bar{U}$, where $P=\{z \in \mathbb{C}: 0 \prec$ $z\}$.

Then $F(0, \cdot)$ has a fixed point if and only if $F(1, \cdot)$ has a fixed point.

Proof. Suppose that $F(0, \cdot)$ has a fixed point $z$; so $z \in F(0, z)$. From (a), $z \in U$. Define the following set:

$$
\mathbb{Q}:=\{(t, \zeta) \in[0,1] \times U: \zeta \in F(t, \zeta)\} .
$$
follows:

Clearly, $\mathbb{Q} \neq \emptyset$. We define the partial ordering $\precsim$ in $\mathbb{Q}$ as

$$
\begin{gathered}
(t, \zeta) \preceq(s, \zeta) \Longleftrightarrow t \leq s, \\
d(\zeta, \zeta) \leq \frac{2}{1-k}(\varphi(s)-\varphi(t)) .
\end{gathered}
$$

Let $\mathscr{M}$ be a totally ordered subset of $Q$ and $\dot{t}=\sup \{t$ : $(t, \zeta) \in \mathscr{M}\}$. Consider a sequence $\left\{\left(t_{n}, \zeta_{n}\right)\right\}$ in $\mathscr{M}$ such that $\left(t_{n}, \zeta_{n}\right) \precsim\left(t_{n+1}, \zeta_{n+1}\right)$ and $t_{n} \rightarrow \stackrel{\circ}{t}$ as $n \rightarrow \infty$. Then, for any $n \geq 1$ with $m>n$, we have

$$
d\left(\zeta_{m}, \zeta_{n}\right) \preceq \frac{2}{1-k}\left(\varphi\left(t_{m}\right)-\varphi\left(t_{n}\right)\right) \longrightarrow 0
$$

as $n, m \rightarrow \infty$, which implies that $\left\{\zeta_{n}\right\}$ is a Cauchy sequence. Since $(X, d)$ is a complete complex valued metric space, there exists $\stackrel{\zeta}{\zeta} \in X$ such that $\zeta_{n} \rightarrow \dot{\zeta}$. From (a), choose $n_{0} \in \mathbb{N}$ such that for all $n \geq n_{0}$,

$$
\begin{aligned}
& \operatorname{ad}\left(\stackrel{\circ}{\zeta}, F\left(t_{n}, \zeta_{n}\right)\right)+b d\left(\zeta_{n}, F(\stackrel{\circ}{t}, \stackrel{\circ}{\zeta})\right) \\
& +c \frac{d\left(\dot{\zeta}, F\left(t_{n}, \zeta_{n}\right)\right) d\left(\zeta_{n}, F(\dot{\circ}, \dot{\zeta})\right)}{1+d\left(\zeta_{n}, \dot{\zeta}\right)} \\
& \in s\left(F\left(t_{n}, \zeta_{n}\right), F(\stackrel{\circ}{t}, \stackrel{\circ}{\zeta})\right), \\
& \operatorname{ad}\left(\stackrel{\circ}{\zeta}, F\left(t_{n}, \zeta_{n}\right)\right)+b d\left(\zeta_{n}, F(\stackrel{\circ}{t}, \stackrel{\circ}{\zeta})\right) \\
& +\frac{c d\left(\dot{\zeta}, F\left(t_{n}, \zeta_{n}\right)\right) d\left(\zeta_{n}, F(\dot{t}, \dot{\zeta})\right)}{1+d\left(\zeta_{n}, \dot{\zeta}\right)} \\
& \in s\left(\zeta_{n}, F(\stackrel{\circ}{t}, \stackrel{\circ}{\zeta})\right)
\end{aligned}
$$

since $\zeta_{n} \in F\left(t_{n}, \zeta_{n}\right)$. So there exists $\zeta_{k} \in F(\dot{t}, \dot{\zeta})$ such that

$$
\begin{aligned}
d\left(\zeta_{n}, \zeta_{k}\right) \leq & a d\left(\dot{\zeta}, F\left(t_{n}, \zeta_{n}\right)\right)+b d\left(\zeta_{n}, F(\stackrel{\circ}{t}, \dot{\zeta})\right) \\
& +\frac{c d\left(\dot{\zeta}, F\left(t_{n}, \zeta_{n}\right)\right) d\left(\zeta_{n}, F(\stackrel{\circ}{t}, \dot{\zeta})\right)}{1+d\left(\zeta_{n}, \stackrel{\zeta}{\zeta}\right)} .
\end{aligned}
$$

By using the g.l.b property of $F$, we get

$$
d\left(\zeta_{n}, \zeta_{k}\right) \leq a d\left(\dot{\zeta}, \zeta_{n}\right)+b d\left(\zeta_{n}, \zeta_{k}\right)+\frac{c d\left(\dot{\zeta}_{,}, \zeta_{n}\right) d\left(\zeta_{n}, \zeta_{k}\right)}{1+d\left(\zeta_{n}, \dot{\zeta}\right)},
$$

which implies that

$$
\begin{aligned}
\left|d\left(\zeta_{n}, \zeta_{k}\right)\right| \leq & a\left|d\left(\dot{\zeta}, \zeta_{n}\right)\right|+b\left|d\left(\zeta_{n}, \zeta_{k}\right)\right| \\
& +c\left|\frac{d\left(\grave{\zeta}, \zeta_{n}\right)}{1+d\left(\zeta_{n}, \dot{\zeta}\right)}\right| d\left(\zeta_{n}, \zeta_{k}\right) \mid .
\end{aligned}
$$

Since $\left|1+d\left(\zeta_{n}, \stackrel{\circ}{\zeta}\right)\right|>\left|d\left(\zeta_{n}, \stackrel{\circ}{\zeta}\right)\right|$, so we have

$$
\begin{gathered}
\left|d\left(\zeta_{n}, \zeta_{k}\right)\right| \leq a\left|d\left(\check{\zeta}_{,} \zeta_{n}\right)\right|+b\left|d\left(\zeta_{n}, \zeta_{k}\right)\right|+c\left|d\left(\zeta_{n}, \zeta_{k}\right)\right|, \\
\left|d\left(\zeta_{n}, \zeta_{k}\right)\right| \leq \frac{a}{1-b-c}\left|d\left(\zeta_{n}, \dot{\zeta}\right)\right| .
\end{gathered}
$$


Note that

$$
\begin{aligned}
\left|d\left(\dot{\zeta}, \zeta_{k}\right)\right| & \leq\left|d\left(\dot{\zeta}, \zeta_{n}\right)\right|+\left|d\left(\zeta_{n}, \zeta_{k}\right)\right| \\
& \leq\left|d\left(\dot{\zeta}, \zeta_{n}\right)\right|+\frac{a}{1-b-c}\left|d\left(\zeta_{n}, \dot{\zeta}\right)\right| \rightarrow 0
\end{aligned}
$$

for all $n \geq n_{0}$. Thus $\zeta_{k} \rightarrow \dot{\zeta} \in F(\dot{\circ}, \dot{\zeta})$ and hence $\dot{\zeta} \in U$, which implies that $(\stackrel{\circ}{t}, \dot{\zeta}) \in Q$ Q Thus, $(t, \zeta) \precsim(\stackrel{\circ}{t}, \dot{\zeta})$ for all $(t, \zeta) \epsilon$ $\mathscr{M}$; that is, $(\dot{t}, \dot{\zeta})$ is an upper bound of $\mathscr{M}$. Hence, by Zorn's Lemma, $Q$ has the maximal element $(\dot{t}, \dot{\zeta})$.

Now, we claim that $\dot{t}=1$. Suppose that $\dot{t} \leq 1$. Choose $0 \prec r \in \mathbb{C}$ and $\dot{t} \leq t$ such that $\bar{B}(\dot{\zeta}, r) \subset U$, where $r=(2 /(1-$ $k))(\varphi(t)-\varphi(t))$. Using (c), we have

$$
\begin{gathered}
\varphi(t)-\varphi(\stackrel{\circ}{t}) \in s(F(t, \zeta), F(\stackrel{\circ}{t}, \dot{\zeta})), \\
\varphi(t)-\varphi(\stackrel{\circ}{t}) \in s(\stackrel{\circ}{\zeta}, F(t, \zeta))
\end{gathered}
$$

for all $\dot{\zeta} \in F(\dot{t}, \dot{\zeta})$. So there exists $\zeta \in F(t, \zeta)$ such that $\varphi(t)-$ $\varphi(\stackrel{\circ}{t}) \in s(d(\dot{\zeta}, \zeta))$ and so

$$
d(\zeta, \dot{\zeta}) \preceq \varphi(t)-\varphi(\stackrel{\circ}{t}) \preceq \frac{(1-k) r}{2} \prec(1-k) r
$$

which implies that

$$
|d(\zeta, \dot{\zeta})| \leq(1-k)|r|
$$

Also, by using (b), we conclude that the mapping $F(t, \cdot)$ : $\bar{B}(\dot{\zeta}, r) \rightarrow C B(X)$ satisfies all the assumptions of Corollary 22 for all $t \in[0,1]$. Hence, for all $t \in[0,1]$, there exists $\zeta \in$ $\bar{B}(\dot{\zeta}, r)$ such that $\zeta \in F(t, \zeta)$. Thus, $(\zeta, t) \in \mathbb{Q}$.

Consider

$$
d(\zeta, \stackrel{\zeta}{\zeta}) \prec r=\frac{2}{1-k}(\varphi(t)-\varphi(\stackrel{\circ}{t}))
$$

which implies that $(\stackrel{\circ}{t}, \dot{\zeta}) \precsim(t, \zeta)$, which is a contradiction. Thus, we have $\dot{t}=1$. Therefore, $F(\cdot, 1)$ has a fixed point.

Conversely, if $F(1, \cdot)$ has a fixed point, then, in the same way, we can prove that $F(0, \cdot)$ has a fixed point. This completes the proof.

\section{Conflict of Interests}

The authors declare that there is no conflict of interests regarding the publication of this paper.

\section{Acknowledgment}

The authors would like to thank the Faculty of Science, Naresuan University, Phitsanulok, Thailand, for the financial support.

\section{References}

[1] S. Banach, "Sur les opérations dans les ensembles abstraits et leurs applications aux équations intégrales," Fundamenta Mathematicae, vol. 3, pp. 133-181, 1922.

[2] S. B. Nadler, "Multi-valued contraction mappings," Pacific Journal of Mathematics, vol. 30, pp. 475-488, 1969.

[3] L.-G. Huang and X. Zhang, "Cone metric spaces and fixed point theorems of contractive mappings," Journal of Mathematical Analysis and Applications, vol. 332, no. 2, pp. 1468-1476, 2007.

[4] M. Arshad, A. Azam, and P. Vetro, "Some common fixed point results in cone metric spaces," Fixed Point Theory and Applications, vol. 2009, Article ID 493965, 11 pages, 2009.

[5] A. Azam and M. Arshad, "Common fixed points of generalized contractive maps in cone metric spaces," Iranian Mathematical Society, vol. 35, no. 2, pp. 255-264, 2009.

[6] A. Latif and F. Y. Shaddad, "Fixed point results for multivalued maps in cone metric spaces," Fixed Point Theory and Applications, vol. 2010, Article ID 941371, 2010.

[7] E. Karapınar, "Some nonunique fixed point theorems of Ciric type on cone metric spaces," Abstract and Applied Analysis, vol. 2010, Article ID 123094, 14 pages, 2010.

[8] E. Karapinar, P. Kumam, and W. Sintunavarat, "Coupled fixed point theorems in cone metric spaces with a $c$-distance and applications," Fixed Point Theory and Applications, vol. 2012, article 194, 2012.

[9] A. Azam, B. Fisher, and M. Khan, "Common fixed point theorems in complex valued metric spaces," Numerical Functional Analysis and Optimization, vol. 32, no. 3, pp. 243-253, 2011.

[10] F. Rouzkard and M. Imdad, "Some common fixed point theorems on complex valued metric spaces," Computers \& Mathematics with Applications, vol. 64, no. 6, pp. 1866-1874, 2012.

[11] W. Sintunavarat and P. Kumam, "Generalized common fixed point theorems in complex valued metric spaces and applications," Journal of Inequalities and Applications, vol. 2012, article 84, 2012.

[12] M. Abbas, M. Arshad, and A. Azam, "Fixed points of asymptotically regular mappings in complex-valued metric spaces," Georgian Mathematical Journal, vol. 20, no. 2, pp. 213-221, 2013.

[13] M. Abbas, B. Fisher, and T. Nazir, "Well-Posedness and periodic point property of mappings satisfying a rational inequality in an ordered complex valued metric space," Numerical Functional Analysis and Optimization, vol. 243, 2011.

[14] M. Arshad and J. Ahmad, "On multivalued contractions in cone metric spaces with out normality," The Scientific World Journal, vol. 2013, Article ID 481601, 3 pages, 2013.

[15] C. Klin-eam and C. Suanoom, "Some common fixed-point theorems for generalized-contractive-type mappings on complexvalued metric spaces," Abstract and Applied Analysis, vol. 2013, Article ID 604215, 6 pages, 2013.

[16] M. A. Kutbi, J. Ahmad, and A. Azam, "On fixed points of $\alpha$ - $\psi$-contractive multivalued mappings in cone metric spaces," Abstract and Applied Analysis, vol. 2013, Article ID 313782, 6 pages, 2013.

[17] M. A. Kutbi, J. Ahmad, N. Hussain, and M. Arshad, "Common fixed point results for mappings with rational expressions," Abstract and Applied Analysis, vol. 2013, Article ID 549518, 11 pages, 2013.

[18] W. Sintunavarat, Y. J. Cho, and P. Kumam, "Urysohn integral equations approach by common fixed points in complex-valued 
metric spaces," Advances in Difference Equations, vol. 2013, article 49, 2013.

[19] K. Sitthikul and S. Saejung, "Some fixed point theorems in complex valued metric spaces," Fixed Point Theory and Applications, vol. 2012, article 189, 2012. 


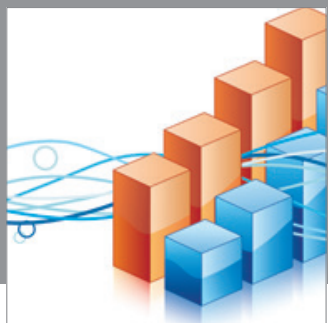

Advances in

Operations Research

mansans

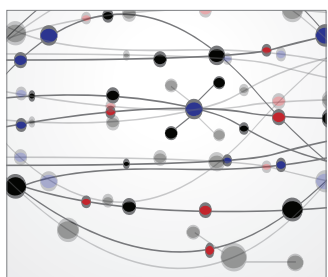

The Scientific World Journal
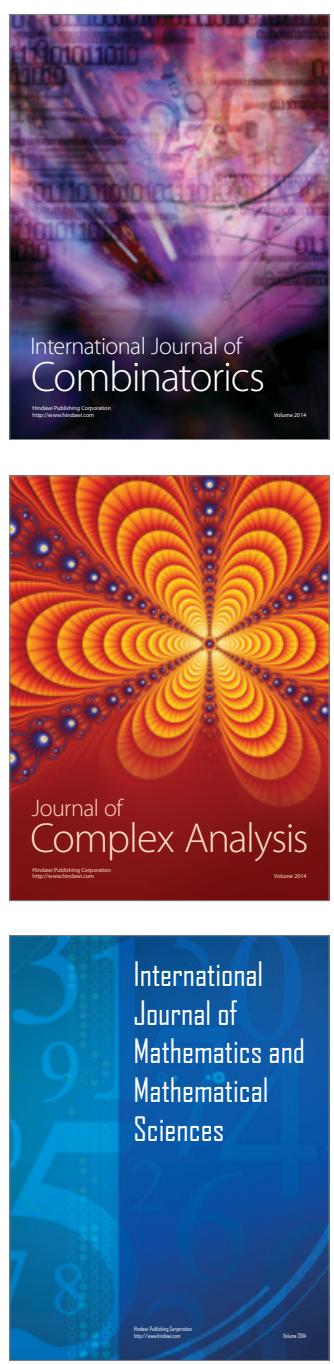
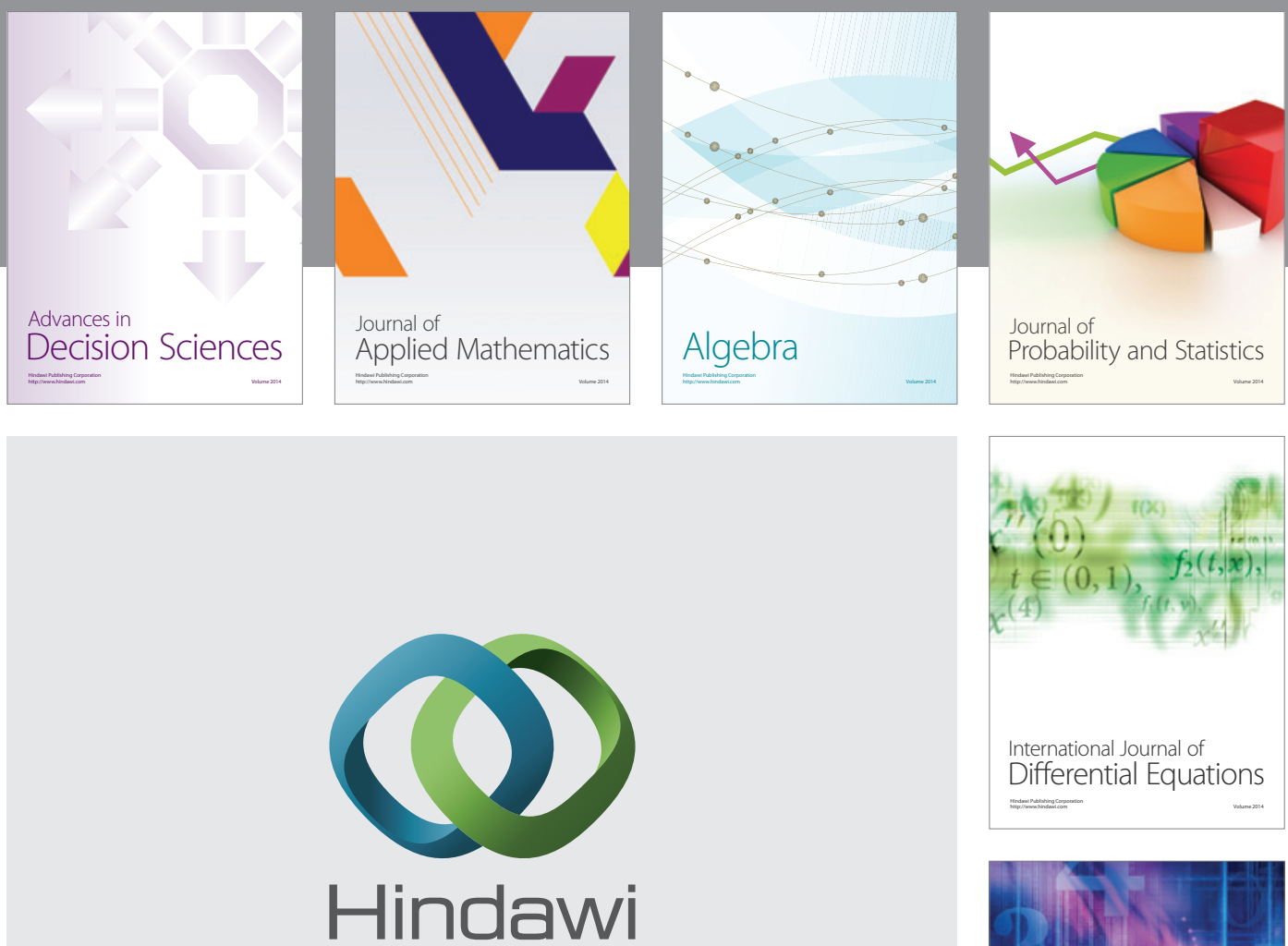

Submit your manuscripts at http://www.hindawi.com
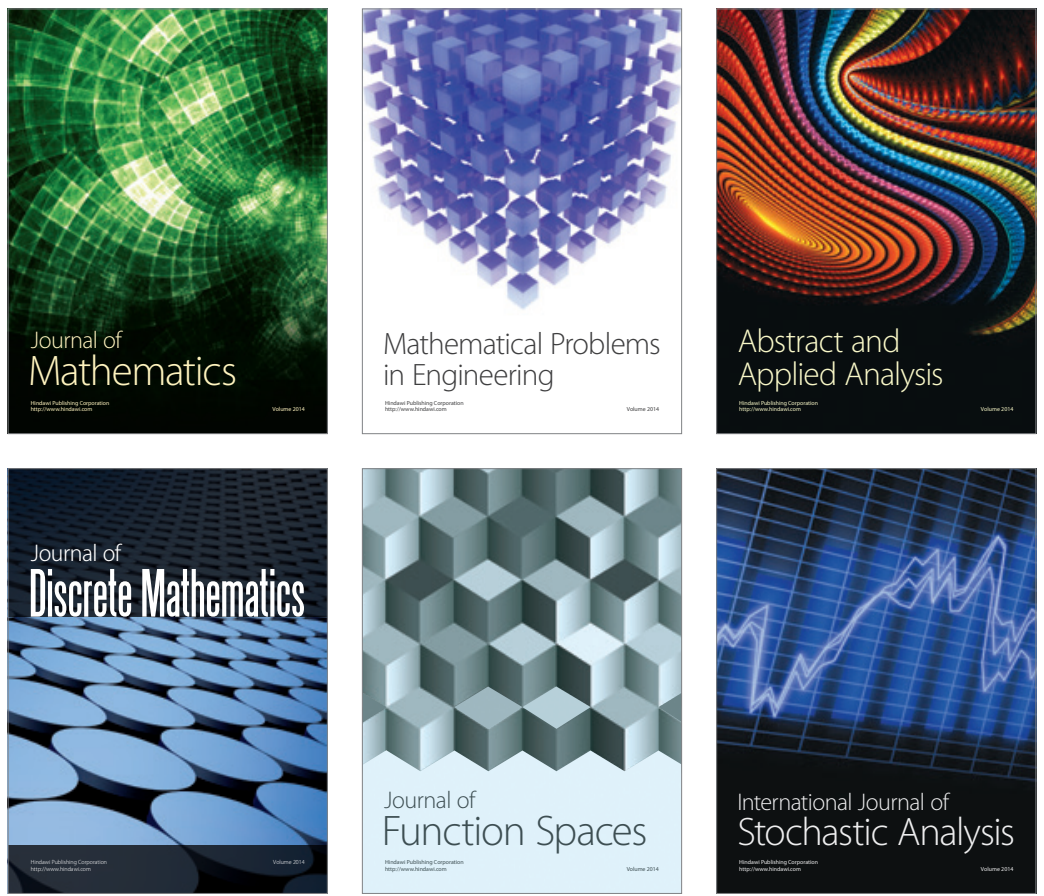

Journal of

Function Spaces

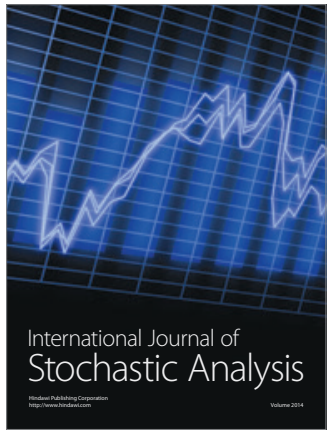

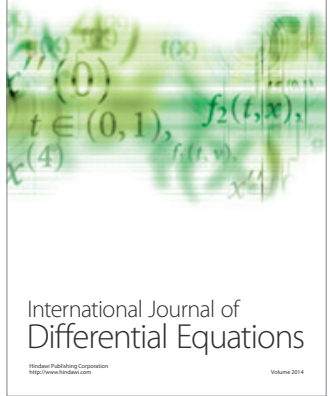
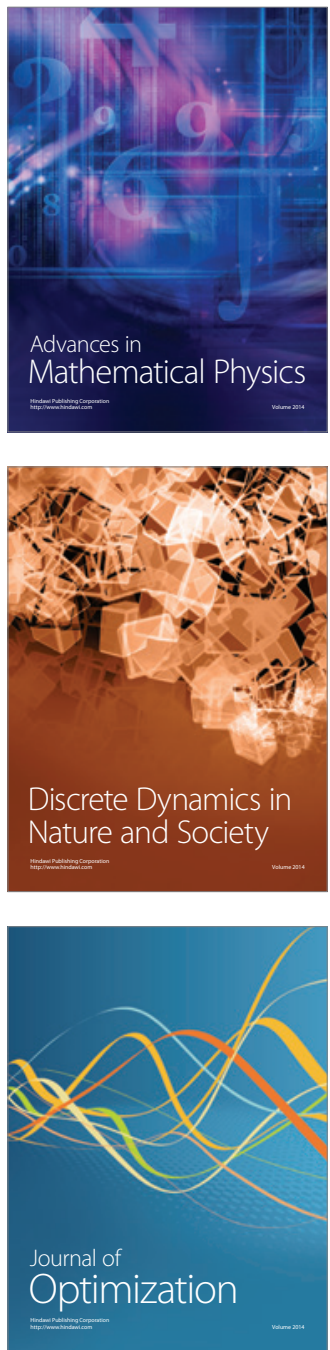